\title{
CFD Simulation of the Air Flow Field in the Multi Blade Centrifugal Fan
}

\author{
Jiawei $\mathrm{Li}^{*}$
}

\author{
Wuchang Institute of Technology, Wuhan, China
}

\begin{abstract}
In this paper, the multi blade centrifugal fan parameter CAD/CFD was developed. Before treatment with the traditional design method as the foundation, use AutoCAD as development of the embedded language. The work of this regulation to establish a set of more perfect design and optimization program of axial flow fan in air, improve its economy, and provided a shortcut for energy saving and noise reduction of multi blade centrifugal machine. Also in the establishment and the simplification of complex models, mesh generation, calculation and other aspects of the use of the model to do some beneficial exploration, hoping to provide reference of the similar simulation numerical type. Influence on the performance of multi blade centrifugal fan impeller is the largest parameters such as the blade outlet angle, inlet angle and blade number. As the numerical simulation application in modern design method, in order to improve the performance of pressure air fan as the optimization objective, the optimization of the fan, the fan impeller optimization parameters more reasonable flow field distribution, air pressure with better performance is obtained, and the formula to determine the recommended number of leaves.
\end{abstract}

Keywords: CFD, fluent, noise reduction, second development.

\section{INTRODUCTION}

Multi blade centrifugal fan is a kind of special structure, while it with centrifugal fan in general, the efficiency is low, but because of its high pressure coefficient of flow coefficient, flow rate and pressure to meet certain requirements with small volume, low noise advantages has been widely used for air conditioning system [1]. Fan performance directly affects the quality of the air conditioning system, air conditioning system for fan performance optimization requirements are also getting higher and higher. Especially in the central air conditioning system in people want to meet the low noise at the same time, air conditioning fan can send more air volume in the air; can achieve the same case, fan can produce higher static pressure to overcome the resistance in the air pipeline, meet more large space air conditioning, reduce air conditioning system the pipeline equipment installation [2].

Although the multi blade centrifugal fan for airconditioner has a long history, but to the design method of theoretical research is relatively less, the lack of specialized industry production enterprises with the design theory [3]. Because of multi blade centrifugal fan for air-conditioner use occasions, focus on design and structure of the particularity, long-term since, multi blade centrifugal fan in general engineering design method is still the design theory of wind turbine follow action, according to the ideal one-dimensional or two-dimensional flow energy equation and continuity equation, the velocity triangle, import and export, at the same time to carry out specific design with some experience of empirical data and design guidelines [4]. This method has the characteristics of simple, but the lack of scientific accuracy, product performance is difficult to grasp, to rely on a large number of tests in order to develop a good product [5].

Multi blade centrifugal fan is the remarkable characteristics of the rotor width / diameter is relatively large, more leaves, can obtain the high pressure and large air volume at a low speed, and the noise is relatively low. So it is widely used in high pressure large volume low noise and smaller installation space usage. This paper summarizes the multi blade centrifugal fan in the traditional design methods, points out the choice of this kind of design method of structural parameters has great uncertainty. This method leads to a variety to find out the solution scheme of model test and a lot of work to do.

\section{RELATED METHOD AND THEORY}

\subsection{Differential Control Equation}

The internal flow of centrifugal fan for the turbulent viscous flow, follow the mass conservation and momentum conservation law, meet the mass continuity equation and motion equation of viscous fluid. CFD analysis using FLUENT software to provide the pressure correction method is used to solve the problem [6].

The mass conservation equation:

$$
\frac{\partial \rho}{\partial t}+\operatorname{div}(\rho \bar{u})=0
$$

The law of conservation of momentum equation:

$$
\frac{\partial}{\partial t}(\rho u)+\operatorname{div}(\rho \bar{u} u)=\operatorname{div}(\mu \operatorname{grad} u)-\frac{\partial \rho}{\partial x}
$$


In flow problems needed solving main variables into the following general form:

$\frac{\partial}{\partial t}(\rho \phi)+\operatorname{div}(\rho \bar{u} \phi)=\operatorname{div}(\Gamma \operatorname{grad} \phi)+S$

$\phi$ : dependent variable

$\rho:$ density

$\bar{u}:$ velocity vector

$\Gamma$ : diffusion coefficient, the meaning is different respect to different $\phi$

$S$ : source term, the meaning is different respect to different $\phi$

\subsection{The Reynolds Equations}

In the Reynolds equation method, and the Reynolds stress equation and the turbulent viscosity coefficient method two categories. The turbulent viscosity method (traditionally called turbulent viscosity coefficient method is a method of calculating flow) and the most widely used numerical [7].

According to the Reynolds average method, random variable is defined as the time average value:

$$
\begin{gathered}
\bar{\phi}=\frac{1}{\Delta t} \int_{t}^{t+\Delta t} \phi(t) d t \\
\overline{\phi^{t}}=0 ; \overline{\bar{\phi}}=\bar{\phi} ; \overline{\bar{\phi}+\phi^{t}}=\bar{\phi} \\
\overline{\overline{\phi f}}=\overline{\phi f} ; \overline{\bar{\phi} f^{\prime}}=0 ; \overline{\bar{\phi} f^{\prime}}=\overline{\phi f} ; \overline{\phi f}=\overline{\phi f}+\overline{\phi^{\prime} f^{\prime}} \\
\overline{\frac{\partial \phi}{\partial x_{i}}}=\frac{\partial \bar{\phi}}{\partial x_{i}} ; \frac{\overline{\partial \phi}}{\partial t}=\frac{\partial \bar{\phi}}{\partial t} ; \frac{\partial^{2} \phi}{\partial x^{2}}=\frac{\partial^{2} \bar{\phi}}{\partial x^{2}} \\
\frac{\overline{\partial \phi}}{\partial x_{i}}=0 ; \frac{\partial^{2} \phi}{\partial x_{i}^{2}}=0
\end{gathered}
$$

4. Then use the rate of pressure solution of turbulent energy of the scalar equation obtained;

5. Check whether the convergence, convergence of iterative computation is stopped, otherwise it returns the first step.

The solving process of independent solution can be expressed in the following diagram (Fig. 1).

\section{EXPERIMENTAL RESULTS}

\subsection{Optimization of Numerical Simulation of Multi Blade Centrifugal Fan}

Design of multi blade centrifugal fan with the traditional design theory, the fan impeller inlet and outlet angle, number of blades and some have important effects on the fan performance parameters have great uncertainty in the selection, so the product scheme design is not necessarily the optimal solution, flow rate, pressure is not up to the requirements often appear to cause engineering products, so people of multi blade centrifugal fan structure parameters optimization of the test.

Pt is caused by the pressure fluctuation velocity:

$p_{t}=\frac{1}{3} \rho\left(\overline{u^{\prime 2}}+\overline{v^{\prime 2}}+\overline{w^{\prime 2}}\right)=\frac{2}{3} p k$

where $\mathrm{k}$ is the unit mass fluid flow:

$k=\frac{1}{2}\left(\overline{u^{\prime 2}}+\overline{v^{\prime 2}}+\overline{w^{\prime 2}}\right)$
As shown in Table $\mathbf{1}$ and figure in the channel, leaves were counterclockwise number, respectively, by $1 \#, 1$ serial number, $\varphi$ is volute spiral angle.

\subsection{Analysis of Flow Field Characteristics of Wind Turbine}

The wind machine is designed in accordance with the best operating point, when the fan in the operation of the small flow rate condition, the performance of non steady state. At this time, the interior flow of air duct complicated. The typical characteristics of the curve in Fig. (2) flow fan. 


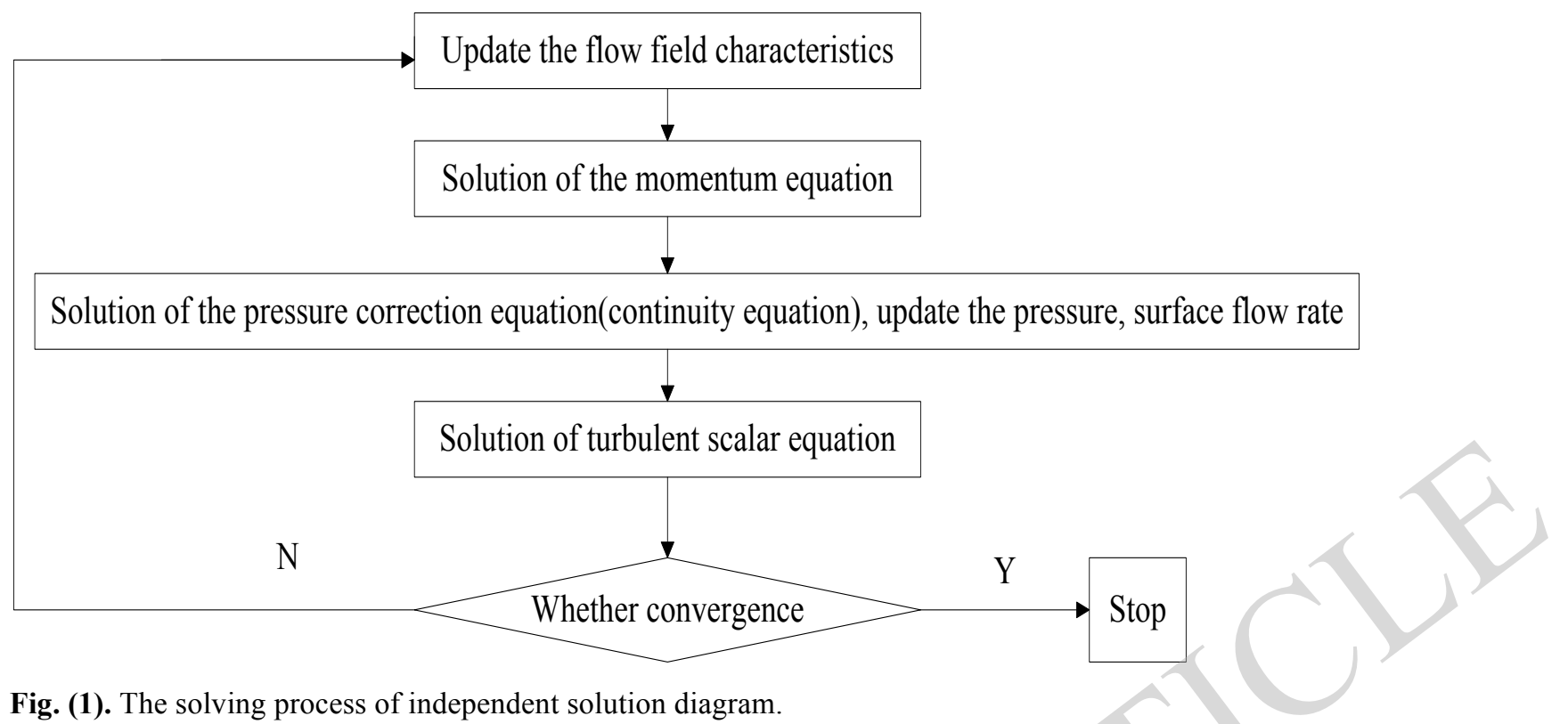

Fig. (1). The solving process of independent solution diagram.

Table. 1. Impeller parameters with different design scheme.

\begin{tabular}{|c|c|c|c|}
\hline $\begin{array}{c}\text { Design } \\
\text { Scheme }\end{array}$ & $\begin{array}{c}\text { Inlet } \\
\text { Angle } \beta_{1 A}\end{array}$ & $\begin{array}{c}\text { Outlet } \\
\text { Angle } \beta_{2 A}\end{array}$ & $\begin{array}{c}\text { Impeller } \\
\text { Diameter (mm) }\end{array}$ \\
\hline \hline $1 \#$ & $54.0^{\circ}$ & $155^{\circ}$ & 103.45 \\
\hline $2 \#$ & $66.0^{\circ}$ & $165^{\circ}$ & 105.04 \\
\hline $3 \#$ & $60.0^{\circ}$ & $160^{\circ}$ & 104.14 \\
\hline
\end{tabular}

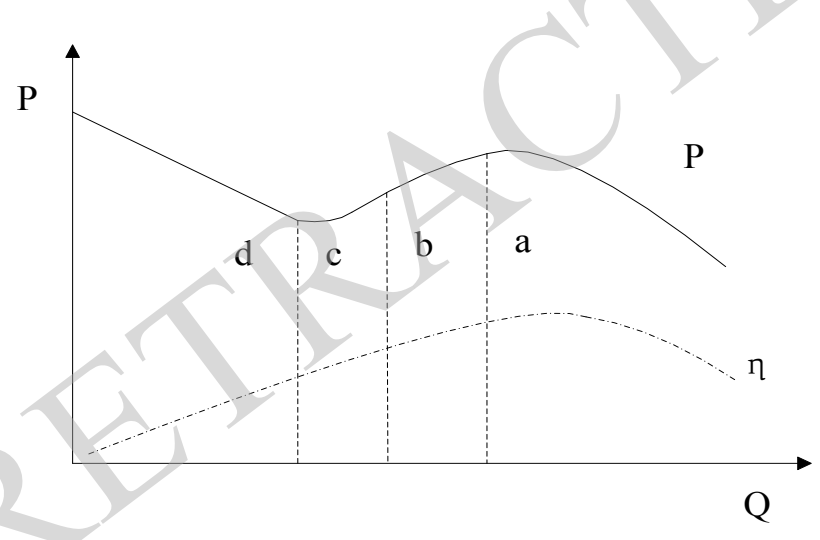

typical characteristics curves of axial flow wind turbine

Fig. (2). The typical characteristics of the curve in flow fan.

The airflow around the wing surface smoothly through the upper wheel hub surface no separation and vortex phenomenon, indicating that the fan root shape and installation angle of reasonable design. Air inlet to outlet total pressure variation curve was shown in Fig. (3).

\subsection{Experiment and Analysis}

Three different schemes of fan whole flow total pressure, static pressure and dynamic pressure distribution is the same: the distribution centers, in the radial direction from the fan impeller inlet to outlet flow part of total pressure, dynamic pressure are steadily increasing, which is due to the reason of impeller fluid power; but in the from the exit of the impeller volute casing wall to import into a dynamic pressure gradually decreased, static pressure, total pressure, static pressure, little change, dynamic pressure drop of fluid is volute diffuser, recovery of the kinetic energy of the performance [9-10].

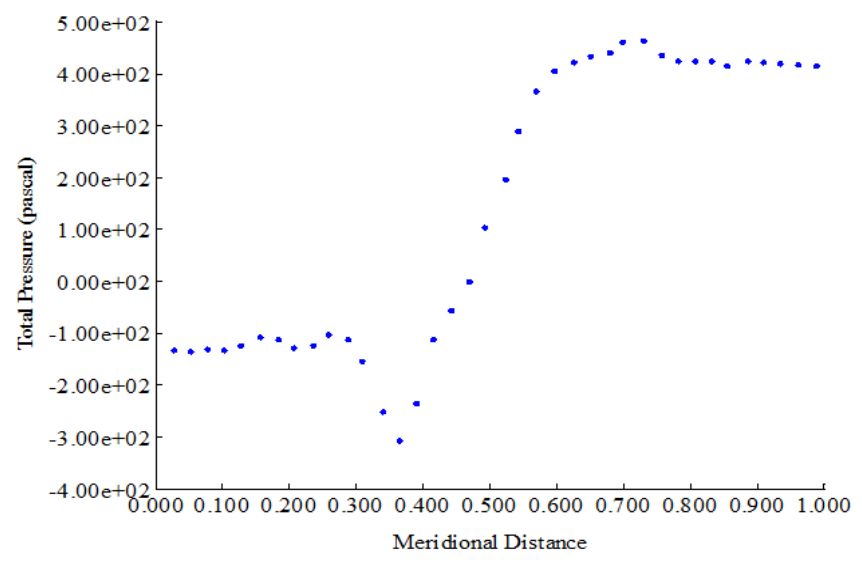

Fig. (3). Air inlet to outlet total pressure variation curve.

The circumferential stress is not symmetry distribution: in the impeller region near the volute outlet total pressure, the dynamic pressure is very high, the total pressure and dynamic pressure in the spiral case of low helix angle small area; and the static pressure distribution trend is just the opposite, in the impeller region on the outlet pressure is low, it is described in the forward multi blade centrifugal fan full pressure in dynamic pressure accounted for a larger proportion, the forward multi blade centrifugal fan with low degree of reaction. In the presence of a local high pressure area of the volute tongue head, it is the high pressure leads to the noise of the fan in the volute tongue. The distribution of $3 \#$ fan whole flow field pressure was shown in Fig. (4). 

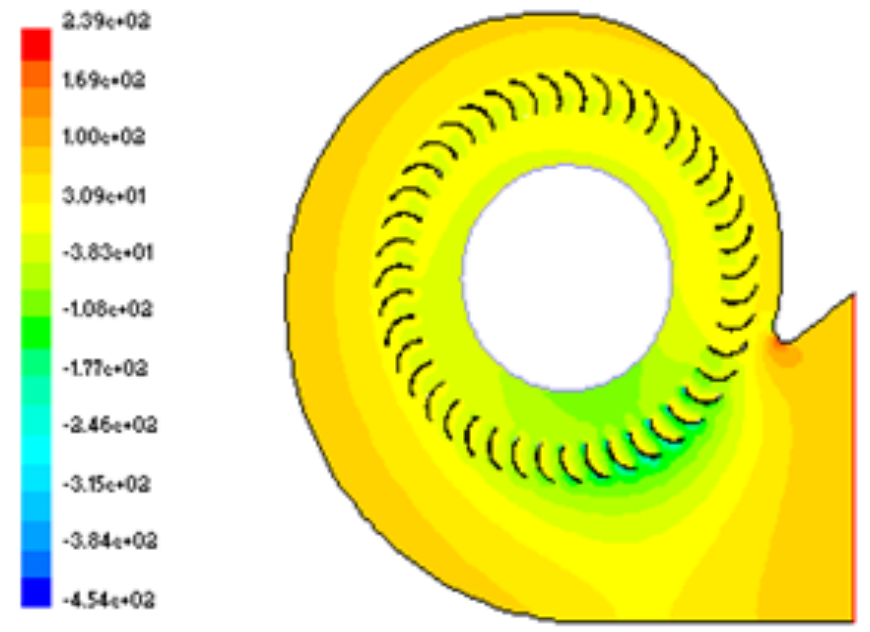

3\# fan static pressure distribution
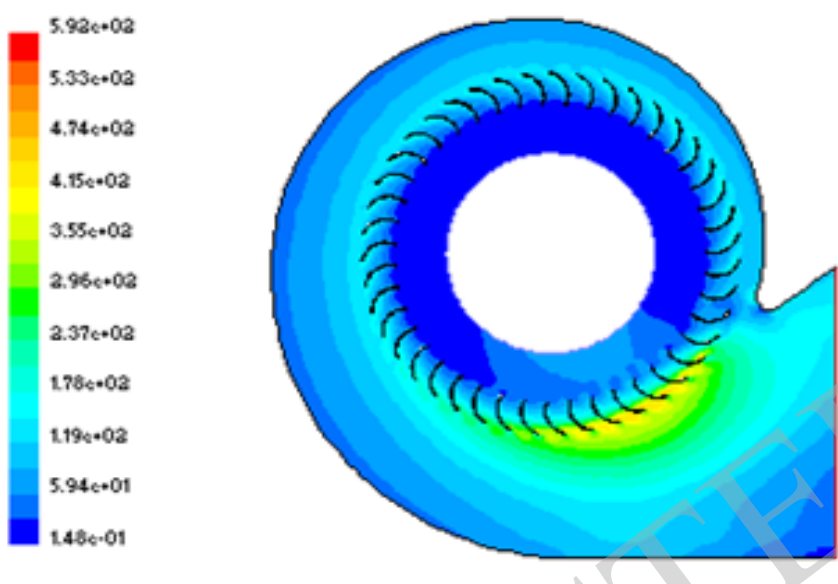

3\# wind pressure distribution scheme of maneuver

Fig. (4). The distribution of $3 \#$ fan whole flow field pressure.

\section{CONCLUSION}

Fan product development process is the traditional conventional design, prototype production, prototype test, repeated production prototype and tested until the development of a product. The prototype production and test not only high cost, and long cycle, so that the product development cycle is longer. The development of numerical simulation technology to the traditional design method to transform to the modern design method, the modern design method is difficult in CFD numerical simulation, and the CAD modeling and meshing simulation model for the workload of CFD value $80 \%$. Simulation of a variety of design schemes were selected and optimized by numerical, replace and reduce the test to a certain extent, so as to shorten the product design cycle, reduce product development costs, but also to ensure the quality of the product.

\section{CONFLICT OF INTEREST}

The authors confirm that this article content has no conflict of interest.

\section{ACKNOWLEDGEMENTS}

Made by Green Fan and Invested by Coordinate Innovation Center of Hubei Province.

\section{REFERENCES}

[1] P. Dilin, "A computational and experimental evaluation of the performance of a centrifugal fan volute," In: Proceedings of the Institution of Mechanical Engineers, Part A, Journal of Power and Energy [H.W. Wilson - AST], vol. 212, no.4, pp. 235-243, 1998.

[2] R. Ramponi, and B. Blocken, "CFD simulation of cross-ventilation for a generic isolated building: impact of computational parameters," Building and Environment, vol. 53, pp. 34-48, 2012.

[3] B. Blocken, W. D. Janssen, and T. van Hooff, "CFD simulation for pedestrian wind comfort and wind safety in urban areas: General decision framework and case study for the Eindhoven University campus," Environmental Modelling \& Software, vol. 30, pp. 15-34, 2012.

[4] J. Franke, A. Hellsten, K. H. Schlunzen, and B. Carissimo, "The COST 732 Best Practice Guideline for CFD simulation of flows in the urban environment: a summary," International Journal of Environment and Pollution, vol. 44, no.1, pp. 419-427, 2011.

[5] H. Ding, F. C. Visser, Y. Jiang, and M. Furmanczyk, "Demonstration and validation of a 3D CFD simulation tool predicting pump performance and cavitation for industrial applications," Journal of Fluids Engineering, vol. 133, no.1, pp. 011101, 2011.

[6] H. Montazeri, B. Blocken, J. L. M. Hensen, "Evaporative cooling by water spray systems: CFD simulation, experimental validation and sensitivity analysis," Building and Environment, vol. 83, pp.129-141, 2015.

[7] P. M. O. Gebraad, F. W. Teeuwisse, J. W. Wingerden, P. A Fleming, S. D. Ruben, J. R. Marden, and L. Y. Pao, "Wind plant power optimization through yaw control using a parametric model for wake effects - a CFD simulation study," Wind Energy, 2014.

[8] A. Flaga-Maryanczyk, J. Schnotale, J. Radon, and K. Was, "Experimental measurements and CFD simulation of a ground source heat exchanger operating at a cold climate for a passive house ventilation system," Energy and Buildings, vol. 68, pp. 562$570,2014$.

[9] J. McNaughton, I. Afgan, D. D. Apsley, S. Rolfo, T. Stallard, and P. K. Stansby, "A simple sliding - mesh interface procedure and its application to the CFD simulation of a tidal - stream turbine," International Journal for Numerical Methods in Fluids, vol. 74, no.4, pp.250-269, 2014.

[10] A. Javadi, M. Karbaschi, D. Bastani, J. K. Ferric, V.I. Kovalchukd, N.M. Kovalchuka, K. Javadib, and R. Miller, "Marangoni instabilities for convective mobile interfaces during drop exchange: experimental study and CFD simulation," Colloids and Surfaces A: Physicochemical and Engineering Aspects, vol. 441, pp. 846-854, 2014. 